\title{
Engineered Narrow Size Distribution High Molecular Weight Proteinoids, Proteinoid-Poly(L-Lactic Acid) Copolymers and Nano/Micro-Hollow Particles for Biomedical Applications
}

Michal Kolitz-Domb and Shlomo Margel ${ }^{*}$

The Institute of Nanotechnology and Advanced Materials, Department of Chemistry, Bar-Ilan University, Ramat-Gan, 52900, Israel

\begin{abstract}
Proteinoids are unusual polymers formed by thermal condensation of amino acids. Several types of proteinoids made of one to three different amino acids, in absence or presence, of low molecular weight poly(L-lactic acid) (PLLA), were synthesized. The polymerization kinetics, molecular weights and physical and mechanical properties of these proteinoids were elucidated. The ability to obtain several high-MW durable proteinoids, by using different amino acids as building blocks, along with incorporating PLLA in their structure, yields a new perspective of biodegradable polymers and polymer particles. Under suitable gentle conditions, the proteinoids can self-assemble to form nanoand micron-sized hollow particles of relatively narrow size distribution. This self-assembly process was used for encapsulation of different molecules within the produced proteinoid particles. One of the encapsulated materials used was indocyanine green (ICG), a known and FDA-approved near-IR dye used for medical cancer diagnosis. The ICG-encapsulated proteinoid particles were tested for biodistribution in mice. The proteinoid particles are nontoxic and stable; hence, they may be excellent candidates for various biomedical applications, e.g., cell labeling and separation, controlled release, drug targeting, etc.
\end{abstract}

Keywords: Proteinoid; Self-assembly; Amino acids; Thermal condensation; Microwave polymerization; Encapsulation

\section{Introduction}

Biodegradable polymers have gained great interest in the last years due to their potential use in a wide area of biomedical applications, including the field of drug delivery [1-6]. When designed for use as drug delivery agents, the polymers should meet several required features such as non-toxicity of the polymer itself and its degradation products and the ability to control hydrolysis rate and mechanical properties by simple manipulations [7]. Since the polymers are prepared for medical use, it is apparent that the starting materials and the optional hydrolytic segments of such biodegradable polymers should be non-toxic and water-soluble [8].

In this work, polymers made of natural amino acids are prepared and discussed. When intended for medical use, the biodegradable<smiles>CC(C)CCC(=O)O</smiles><smiles>O=C1CCC(C(=O)O)N1</smiles>

Pyroglutamic acid<smiles>[R]C(N)C(=O)O</smiles><smiles>O=C([O-])NC(=O)O</smiles><smiles>[R]C(C)=CC(=O)NCC</smiles>

\section{$\mathrm{R}=$ any amino- acid side chain}

Scheme 1: Thermal polymerization of amino acids through pyroglutamic acid catalysis. polymer is chosen according to its features serving the designated need. In general, such synthetic polymers may offer greater advantages over natural ones since they can be designed according to the desired use, providing a wide range of desired properties and predictable characteristics. Furthermore, synthetic polymers represent a reliable source of raw materials, free from concerns of infection or immunogenicity [9-11].

Proteinoids, polymers made of amino acids by thermal condensation polymerization, are unique synthetic polymers studied by Fox et al. [12-18]. The amino acids, either natural or synthetic, are polymerized by step-growth polymerization in a special procedure discovered by Fox and Harada [19-23]. The procedure involves heating amino acids until they melt at first, and then the polymerization is initiated to give the proteinoid. The polymerization takes place at a relatively high temperature (e.g., $180^{\circ} \mathrm{C}$ ), in absence of a solvent or a catalyst, and in an inert atmosphere. The accepted explanation of this polymerization process is that glutamic acid is used as a solvent for the other monomers, as it is condensed into pyroglutamic acid. The pyroglutamic acid initiates the polymerization with the rest of the present amino acids [22-25]. A brief description of the polymerization process is shown in Scheme 1.

An important advantage in using biodegradable polymers bearing one or more stereogenic centers- optically active polymers- is the

*Corresponding author: Shlomo Margel, The Institute of Nanotechnology and Advanced Materials, Department of Chemistry, Bar-llan University, Ramat-Gan 52900, Israel, Tel: +972-3-5318861; E-mail: shlomo.margel@mail.biu.ac.il

Received July 16, 2014; Accepted August 08, 2014; Published August 12, 2014

Citation: Kolitz-Domb M, Margel S (2014) Engineered Narrow Size Distribution High Molecular Weight Proteinoids, Proteinoid-Poly(L-Lactic Acid) Copolymers and Nano/Micro-Hollow Particles for Biomedical Applications. J Nanomed Nanotechnol 5: 216. doi: 10.4172/2157-7439.1000216

Copyright: (C) 2014 Kolitz-Domb M, et al. This is an open-access article distributed under the terms of the Creative Commons Attribution License, which permits unrestricted use, distribution, and reproduction in any medium, provided the original author and source are credited. 
Citation: Kolitz-Domb M, Margel S (2014) Engineered Narrow Size Distribution High Molecular Weight Proteinoids, Proteinoid-Poly(L-Lactic Acid) Copolymers and Nano/Micro-Hollow Particles for Biomedical Applications. J Nanomed Nanotechnol 5: 216. doi: 10.4172/21577439.1000216

Page 2 of 10

high variety of features they offer, when used as carriers for drug delivery systems [26]. This study is intended to broaden the scope of biodegradable polymers by synthesizing new proteinoids carrying various stereogenic centers. The main goal is to provide a large choice of biodegradable proteinoids with pre-determined characteristics, while using amino acids as building blocks. Hence, the new selection is based on chiral building blocks carrying positive/negative charge, hydrophilic/hydrophobic nature or any desired combination of the above [27]. Homopolymers, random copolymers and block-copolymers of two amino acids or more can be designed and synthesized, presenting thereby new proteinoid materials with specific, desired nature. The large variety of amino acids, either natural or synthetic, makes it possible to obtain a large library of different proteinoids, by simply changing the amino acids ratios. One proteinoid is completely different from another, by the fact that they are made of different amino acid monomers. This fact provides each proteinoid special features, and possibly influences the character of particles made from it [28-31]. Up until now, most, if not all, of the reported proteinoids in the literature were synthesized from at least seven amino acids and possessed relatively low molecular weights. Thus, high molecular weight proteinoids made of two to three natural amino acids, along with proteinoids containing poly $(\mathrm{L}$ lactic acid) (PLLA) segments are presented for the first time. The high molecular weights of polymers in general, improve the chemical and physical properties, since the intermolecular forces are enhanced between the polymeric chains.

In the present article, several types of new proteinoids were synthesized, using different building blocks. The natural amino acids glutamic acid, aspartic acid, phenylalanine and lysine were used in different proportions in order to obtain proteinoids bearing different characteristics. Also, PLLA was incorporated within the proteinoids in order to affect the physical and chemical properties of the resulted proteinoid and proteinoid particles.

\section{Microwave-assisted polymerization}

The use of microwave for chemical synthesis is gaining growing interest in the last few years [32,33]. Using microwave heating, certain reactions are complete within seconds or minutes. In the field of synthetic polymer chemistry, microwave energy has been used for the polymerization of vinyl monomers, ring opening polymerization of caprolactam and caprolactone [34-36], condensation polymerization of polyesters [11,37,38], polyanhydrides [39], polyamides and polyimides [40]. This study tested this approach as an additional way for the polymerization of amino acids. A comparison between the polymers obtained by the thermal polymerization and the microwave-assisted polymerization was accomplished as well.

\section{Preparation of micro- and nano-sized particles}

After preparation, the crude proteinoids can self-assemble to form micro- and nano-sized particles [41,42]. As opposed to polystyrene microparticles, for example, which are formed during the polymerization process of styrene in the presence of a surfactant [43], the proteinoid particles are formed through a self-assembly process. This process is completed only after the polymerization itself. The procedure involves either dissolving the dried crude proteinoid in water by heating and then cooling slowely [44], or by $\mathrm{pH}$ changes of the proteinoid solution in water [45]. This way, particles of the size range of several nanometers to $10 \mu \mathrm{m}$ may be formed [46]. When the selfassembly procedure is done in the presence of a suitable molecule such as drug or dye, a proteinoid particle containing the molecule is formed [47]. In this work, we encapsulated several molecules within one of the proteinoids: toluene, perfluorohexane, fluorescein, solvent blue 59 and the NIR dye indocyanine green (ICG). The NIR proteinoid particles were tested for biodistribution in a mouse model, showing their ability to penetrate different parts of the body. This way, the proteinoid particles can be used as delivery systems, depending on the proteinoid special features [48-53].

\section{Experimental Section}

\section{Materials}

The following analytical-grade chemicals were purchased from commercial sources and were used without further purification: $(\mathrm{L})$ glutamic acid, (L)aspartic acid, (L)lysine and (L)phenylalanine, sodium chloride, sodium hydroxide $(\mathrm{NaOH} 1 \mathrm{~N})$, hydrochloric acid $(\mathrm{HCl} 1$ $\mathrm{N})$, human serum albumin (HSA), bovine plasma fibrinogen, toluene, perfluorohexane $(\mathrm{PFH})$, solvent blue 59 and fluorescein from Sigma (Rehovot, Israel); Poly(L-lactic acid) (PLLA) MW 2,000 Da from Polysciences (Warrington, PA, USA); Minimum Essential Medium (MEM) eagle, Fetal Bovine Serum (FBS), Phosphate Buffered Saline (PBS), $1 \%$ glutamine, $1 \%$ penicillin/streptomycin and mycoplasma detection kit from Biological Industries (Bet Haemek, Israel); Cytotoxicity detection kit from Roche Diagnostics, USA; Human colon adenocarcinoma LS174t cell line from American Type Culture Collection (ATCC). Water was purified by passing deionized water through an Elgastat Spectrum reverse osmosis system (Elga Ltd., High Wycombe, UK).

\section{Preparation of proteinoids by thermal condensation polymerization}

(L)glutamic acid was heated to the molten state $\left(180^{\circ} \mathrm{C}\right)$ in an oil bath, under nitrogen atmosphere. The molten mass was stirred at $180^{\circ} \mathrm{C}$ for $30 \mathrm{~min}$. To this, different contents of additional (L)amino acids were added to give a total monomer weight of 5-5.01 g, as specified in Table 1 , and kept at $180^{\circ} \mathrm{C}$ under nitrogen. The mixture was mechanically stirred at $150 \mathrm{rpm}$ for $3 \mathrm{~h}$. The product is a highly viscous orangebrown paste, which hardens to give a glassy mass when cooled to room temperature. Then, water $(10 \mathrm{~mL})$ was added to the crude product, and the mixture was stirred for $20 \mathrm{~min}$. The solution was then intensively dialyzed through a cellulose membrane (3500 Da MWCO) against distilled water. The content of the dialysis tube was then lyophilized to obtain a yellow-white proteinoid powder.

Polymerization kinetics was studied by collecting proteinoid samples from the reaction vessel at different time periods of the polymerization at 180,190 and $200^{\circ} \mathrm{C}$. The samples were then analyzed by both ninhydrin test for the determination of the primary amine

\begin{tabular}{|c|c|c|c|c|c|}
\hline \multirow{2}{*}{ Polymer } & \multicolumn{5}{|c|}{ Amino acid content $(\mathbf{g})^{a}$} \\
\hline & (L)Glu & (L)Asp & (L)Lys & (L)Phe & PLLA \\
\hline Prot1 & 5 & - & - & - & - \\
\hline Prot2 & 2.5 & 2.5 & - & - & - \\
\hline Prot $^{b}$ & 0.15 & 0.15 & - & - & - \\
\hline Prot3 & 2.5 & - & - & 2.5 & - \\
\hline Prot4 & 1.25 & 2.5 & - & 1.25 & - \\
\hline Prot5 & 1.67 & 1.67 & 1.67 & - & - \\
\hline Prot6 & 1.67 & - & 1.67 & 1.67 & - \\
\hline Prot7 & 1.25 & - & 2.5 & 1.25 & - \\
\hline Prot8 & 2.25 & - & - & 2.25 & 0.5 \\
\hline
\end{tabular}

aln all proteinoids made by thermal condensation polymerization the total monomer content was 5-5.01 g; ${ }^{b}$ made by microwave-assisted polymerization.

Table 1: Amino acid content of the different proteinoids. 
Citation: Kolitz-Domb M, Margel S (2014) Engineered Narrow Size Distribution High Molecular Weight Proteinoids, Proteinoid-Poly(L-Lactic Acid) Copolymers and Nano/Micro-Hollow Particles for Biomedical Applications. J Nanomed Nanotechnol 5: 216. doi: 10.4172/21577439.1000216

Page 3 of 10

groups content and Biuret test for the determination of the amide groups content of the various proteinoids [54].

\section{Proteinoid analysis and characterization}

Amino acid analysis was carried out using Waters AccQTag method [55]. Before analysis, the material was hydrolyzed by standard acid hydrolysis, using $6 \mathrm{~N} \mathrm{HCl}$ at $110^{\circ} \mathrm{C}$ for $22 \mathrm{~h}$. The molecular weights and polydispersity index of the dried crude proteinoids were determined using Gel Permeation Chromatography (GPC) consisting of a Waters Spectra Series P100 isocratic HPLC pump with an ERMA ERC-7510 refractive index detector and a Rheodyne (Coatati, CA) injection valve with a $20 \mu \mathrm{L}$ loop (Waters, MA). The samples were eluted with super-pure HPLC water through a linear BioSep SEC-s3000 column (Phenomenex) at a flow rate of $1 \mathrm{~mL} / \mathrm{min}$. The molecular weights were determined relative to poly(ethylene glycol) standards (Polymer Standards Service-USA, Silver Spring, MD) with a molecular weight range of 100-450000 Da, Human Serum Albumin (HSA, $67 \mathrm{kDA}$ ) and bovine plasma fibrinogen $(340 \mathrm{kDa})$, using Clarity chromatography software. The optical activities of the proteinoids were determined using a PE 343 polarimeter (PerkinElmer). All of the measurements were done in water, at $589 \mathrm{~nm}$ at $25^{\circ} \mathrm{C}$. Fourier Transform InfraRed (FTIR) measurements of the crude proteinoids were done by the Attenuated Total Reflectance (ATR) technique, using Bruker ALPHA-FTIR QuickSnap ${ }^{\mathrm{TM}}$ sampling module equipped with Platinum ATR diamond module. The thermal behavior of the proteinoids was determined using Differential Scanning Calorimetry (DSC) and Thermo Gravimetric Analysis (TGA) with a TGA/DSC 1 STARe system (Mettler Toledo, Switzerland). The samples were heated between $25-400^{\circ} \mathrm{C}$ at a rate of $10^{\circ} \mathrm{C} / \mathrm{min}$ under nitrogen atmosphere.

\section{Carboxyl group analysis}

The content of free carboxyl groups in the synthesized proteinoids is an essential factor in determining their solubility in different media, thus helping to understand their stability at different sites in the human body with different $\mathrm{pHs}$. In order to determine the free carboxyl groups in the synthesized proteinoids, a titrimetric method was carried out [56]. Briefly, to a known quantity of dry proteinoid, a known excess of $0.05 \mathrm{~N} \mathrm{NaOH}$ was added, followed by the addition of $37 \%$ formaldehyde solution. The unreacted $\mathrm{NaOH}$ was back-titrated with standard $0.05 \mathrm{~N}$ $\mathrm{HCl}$. A blank titration was also performed. In addition, human serum albumin (HSA) was titrated for comparison.

\section{Preparation of proteinoids by microwave-assisted polymerization}

Microwave polymerization method was conducted by a Biotage microwave synthesizer (Biotage Initiator ${ }^{\mathrm{TM}}$ ). Briefly, a mixture of $(\mathrm{L})$ glutamic acid and (L)aspartic acid (150 mg each) was sealed in a 2.0 $5.0 \mathrm{~mL}$ microwave glass vial with a magnetic stirrer. The reaction was irradiated for $60 \mathrm{~min}$ at $120^{\circ} \mathrm{C}$, at a pressure of $0-1$ bar and a power of $200 \mathrm{~W}$ [11,57]. The microwave-made Prot 2 was cleaned, dried and characterized by the same techniques as mentioned above.

\section{Incorporation of poly(L-lactic acid) into the proteinoids}

In order to effect the chemical and physical properties of the product, a thermal polymerization of (L)glutamic acid and (L)phenylalanine was carried out in the presence of low molecular weight poly(L-lactic acid) (PLLA, $2000 \mathrm{Da}$ ). The proteinoid-PLLA (Prot8) consists of 2.25 $\mathrm{g}$ of each amino acid and $0.5 \mathrm{~g}$ of PLLA. After polymerization, it was washed, dried and characterized as described earlier.

\section{Preparation and characterization of proteinoid nano/micro- particles}

Proteinoid particles were prepared by a self-assembly mechanism. Briefly, $100 \mathrm{mg}$ of the dried proteinoid were added to $10 \mathrm{~mL}$ doubledistilled water. The mixture was then heated to $80^{\circ} \mathrm{C}$ until the crude proteinoid dissolves completely. Proteinoid particles were then formed by removal of the heating and leaving the mixture to cool to room temperature. The size and size distribution of the formed proteinoid particles were controlled by changing various parameters of the selfassembly precipitation process, e.g., salt concentration or cooling rate [46]. The obtained particles were dialyzed as previously described to wash off excess reagents. This effect of salt concentration and cooling rate on the size of the proteinoid particles was studied with Prot3.

Hydrodynamic diameter and size distribution of the particles dispersed in double distilled (DD) water were measured at room temperature with a particle DLS analyzer model Nanophox (SympatecGmbH, Germany). Dried particle size and size distribution were measured with a Scanning Electron Microscope (SEM). SEM pictures were obtained with a JEOL, JSM-840 Model, Japan. For this purpose, a drop of dilute particle dispersion in distilled water was spread on a glass surface, and then dried at room temperature. The dried sample was coated with carbon in vacuum before viewing under SEM. The average particle size and distribution were determined by the measurement of the diameter of more than 200 particles with image analysis software (Analysis Auto, Soft Imaging System GmbH, Germany).

The density of the particles was determined by pycnometry [58] Briefly, dry pre-weighed particles were put in a calibrated pycnometer which was then filled with water. The density of the sample can then be calculated from the known density of the water, the weight of the pycnometer filled only with water, the weight of the pycnometer containing both the sample and water, and the weight of the sample, as described in the literature [58].

\section{Cytotoxicity of the proteinoid particles}

In vitro cytotoxicity of the proteinoid particles was tested by using human colon adenocarcinoma LS174T cancer cell line. The tests were done on Prot2, Prot4, Prot5, Prot7 and Prot8. The cell line is adherent to the used culture dishes. LS174T cells were grown in MEM that was supplemented with $10 \%$ heat-inactivated fetal bovine serum (FBS), $1 \%$ glutamine and $1 \%$ penicillin/streptomycin. Cells were screened to ensure they remained mycoplasma-free using Mycoplasma Detection Kit [59].

Cell cytotoxicity was assessed by measuring the release of cytoplasmic lactate dehydrogenase (LDH) into cell culture supernatants. $\mathrm{LDH}$ activity was assayed using the Cytotoxicity Detection Kit according to the manufacturer's instructions [60]. Cells $\left(3 \times 10^{5}\right.$ cells per well) were seeded and grown to $90-95 \%$ confluency in 24 well plates before treatment with the proteinoid particles. Cell cultures that were not exposed to the particles were included in all assays as negative controls. Cell cultures that were treated with $1 \%$ Triton-x-100 were used as positive controls. To test if the particles can interact with LDH kit compounds, cell cultures were exposed to a mixture containing maximal nano/micro-particles concentration dispersed in PBS and $1 \%$ Triton-x-100.

The proteinoid particles were freshly dispersed in PBS (1.25 and $2.5 \mathrm{mg} / \mathrm{mL}$ ) and then added to the 95\% confluent cell culture in culture medium. The cell cultures were further incubated at $37^{\circ} \mathrm{C}$ in a 
Citation: Kolitz-Domb M, Margel S (2014) Engineered Narrow Size Distribution High Molecular Weight Proteinoids, Proteinoid-Poly(L-Lactic Acid) Copolymers and Nano/Micro-Hollow Particles for Biomedical Applications. J Nanomed Nanotechnol 5: 216. doi: 10.4172/21577439.1000216

Page 4 of 10

humidified $5 \% \mathrm{CO}_{2}$ incubator and then checked for cellular cytotoxicity at intervals of $24 \mathrm{~h}$. The percentage of cell cytotoxicity was calculated using the formula shown in the manufacturer's protocol [60]. All samples were tested in tetraplicates.

\section{Particle stability}

Proteinoid particles aqueous dispersions $(1 \mathrm{mg} / \mathrm{mL})$ were put in a refrigerator at $4^{\circ} \mathrm{C}$ for 6 months. Samples were taken at different time periods, filtered through a centrifugation tube (Vivaspin $3000 \mathrm{Da}$ MWCO) and the filtrate was checked by UV at $200-210 \mathrm{~nm}$, to find aqueous soluble proteinoid. Also, the particle aqueous dispersions were checked by Nanophox for their size and size distribution. In order to check the particle stability after drying, the particles were lyophilized to dryness and then dispersed in an aqueous phase to their original concentration. The samples size and size distribution were then rechecked by Nanophox.

\section{Encapsulation of different materials within the particles}

Prot8 was used to encapsulate several materials. To the heated proteinoid mixture $\left(10 \mathrm{mg}\right.$ in $9.8 \mathrm{~mL} \mathrm{NaCl} 10^{-5} \mathrm{~N}$, at $\left.80^{\circ} \mathrm{C}\right), 1 \% \mathrm{w} / \mathrm{w}$ of the wanted material (dissolved in $200 \mu \mathrm{L} \mathrm{NaCl}$ solution) was added. The heating was stopped, the mixture was mechanically stirred at $250 \mathrm{rpm}$ and left to cool to room temperature in order to form the proteinoid particles containing the encapsulated material. The encapsulated materials were toluene, perfluorohexane $(\mathrm{PFH})$, fluorescein, solvent blue 59 dissolved in toluene and indocyanine green (ICG). The particles were washed and characterized as mentioned before for their size and size distribution. Also, the fluorescein and ICG-containing proteinoid particles were characterized by UV and fluorescence. Absorbance spectra were obtained using a Cary 100 UV-Visible spectrophotometer (Agilent Technologies Inc.). Excitation and emission spectra were measured by a Cary eclipse spectrofluorometer (Agilent Technologies, Inc.).

\section{Biodistribution in a mouse model}

Male BALB/C mice (Harlan Laboratories, Israel) were utilized in this study under a protocol approved by the Institutional Animal Care and Use Committee at Bar-Ilan University. The biodistribution of the NIR fluorescent Prot8 nanoparticles was studied in normal 8-weeksold mice, weighing 20-25 g at the time of experiment. Prior to the experiment, mice were anesthetized by intraperitoneal injection of Ketamine $(40-80 \mathrm{mg} / \mathrm{kg}$ body weight) and Xylazine $(5-10 \mathrm{mg} / \mathrm{kg}$ body weight), and the mice's skin was shaved with an electric animal clipper.

$100 \mu \mathrm{L}$ of either nanoparticle dispersion or free ICG solution $(0.01$ $\mathrm{mg} / \mathrm{kg}$ body weight, dissolved in PBS) were administered to the mice through tail vein injection at a concentration of $2 \mathrm{mg} / \mathrm{mL}$. During image acquisition, mice remained anesthetized by the intraperitoneal injection of Ketamine/Xylazine. Image cubes were obtained from the mice at several time points up to $24 \mathrm{~h}$ after injection. Each treatment group includes 3 mice for each time point $(5 \mathrm{~min}, 20 \mathrm{~min}, 1 \mathrm{~h}$ and 24 h); 2 uninjected mice served as negative control. The experiment was repeated twice, testing a total of 52 mice. At the end of the experiment, the mice were euthanized by cervical dislocation, and organs were taken for imaging (liver, spleen, kidney, duodenum, colon, brain, heart, tibia bone and blood).

Fluorescence images were acquired using a Maestro II in vivo fluorescence imaging system (Cambridge Research \&Instrumentation, Inc., Woburn, MA). The system is equipped with a fiber-delivered 300 W xenon excitation lamp, and images can be acquired from $\lambda=500-950$ $\mathrm{nm}$ by a 1.3 megapixel CCD camera (Sony ICX285 CCD chip). Each pixel within the image cube therefore has an associated fluorescence spectrum. The software for the Maestro system (Maestro 2.10.0) contains several algorithms to process the spectral data cubes to remove undesired auto-fluorescence signal and generate overlaid images for multiple fluorophores. A deep red excitation/emission filter set was used for our experiments ( $\lambda$ ex: $700-770 \mathrm{~nm}, \lambda e m>780 \mathrm{~nm}$ ). The liquid crystal tunable filter (LCTF) was programmed to acquire image cubes from $\lambda=780 \mathrm{~nm}-860 \mathrm{~nm}$ with an increment of $10 \mathrm{~nm}$ per image. The camera was set to $150 \mathrm{~ms}$ (whole body image), $15 \mathrm{~ms}$ (liver), $500 \mathrm{~ms}$ (spleen), $7000 \mathrm{~ms}$ (kidney), $10 \mathrm{~ms}$ (duodenum), $500 \mathrm{~ms}$ (colon), 1000 ms (brain), $1000 \mathrm{~ms}$ (tibia bones), $200 \mathrm{~ms}$ (heart) and $1000 \mathrm{~ms}$ (blood) exposure times. Fluorescence intensity measurements were performed using ImageJ NIH (National Institutes of Health) software.

\section{Results and Discussion}

\section{Synthesis and characterization of the proteinoids}

As described above, different proteinoids were prepared by thermal condensation of different monomer contents. Table 2 exhibits the different synthesized proteinoids and their characteristic molecular weights, polydispersity and optical activity.

Table 2 indicates a relatively low PDI values for the obtained proteinoids. This is quite unexpected since the polycondensation of the various amino acids is random. The highest PDI (2.32) was observed for Prot1, composed of the single amino acid (L) glutamic acid, while the PDIs of the other proteinoids composed of at least 2 amino acids range between 1.01 and 1.27. All of the thermally-made proteinoids have relatively high molecular masses of $26-195 \mathrm{kDa}$. This indicates that

\begin{tabular}{|c|c|c|c|c|c|}
\hline Proteinoid $^{a}$ & $\begin{array}{l}M w \\
(D a)^{b}\end{array}$ & $\begin{array}{l}\mathrm{Mn} \\
(\mathrm{Da})^{b}\end{array}$ & $\begin{array}{l}\mathrm{Mp}_{(\mathrm{Da})^{b}} \\
\text { (1) }\end{array}$ & $\mathrm{PDI}^{c}$ & $\begin{array}{l}\text { Optical Activity }[\alpha]_{D}{ }^{25^{\circ} \mathrm{C}} \\
\left(\left(^{\circ}\right)^{d}\right.\end{array}$ \\
\hline Prot1 & 26250 & 11300 & 11320 & 2.32 & +6.5 \\
\hline Prot2 & 181540 & 144940 & 195300 & 1.25 & -4.4 \\
\hline Prot2 $^{e}$ & 500240 & 497280 & 503070 & 1.01 & +8.1 \\
\hline Prot3 & 164930 & 138250 & 158740 & 1.19 & -9.0 \\
\hline Prot4 & 87660 & 84410 & 85250 & 1.04 & -3.3 \\
\hline Prot5 & 195080 & 165870 & 191440 & 1.17 & -7.4 \\
\hline Prot6 & 190390 & 163290 & 204050 & 1.16 & -15.1 \\
\hline Prot7 & 72260 & 56880 & 42870 & 1.27 & +2.8 \\
\hline Prot8 & 168300 & 156600 & 136800 & 1.07 & -4.6 \\
\hline
\end{tabular}

aThe proteinoids were prepared at $180^{\circ} \mathrm{C}$ according to the experimental section; ${ }^{b}$ molecular masses were measured by GPC, Mp is the molecular mass at the peak; ${ }^{c} \mathrm{PD}$ is the polydispersity index, given by $\mathrm{Mw} / \mathrm{Mn}$; ${ }^{d}$ specific optical rotation $\left(\mathrm{c}=1\right.$, in $\mathrm{H}_{2} \mathrm{O}$, at $\left.25^{\circ} \mathrm{C}\right)$; ${ }^{e}$ made by microwave-assisted polymerization. Each experiment was performed 3 times, with an error of $0.5-1.7 \%$

Table 2: Mw, Mn, Mp, PDI and optical activity of the various proteinoids. 
Citation: Kolitz-Domb M, Margel S (2014) Engineered Narrow Size Distribution High Molecular Weight Proteinoids, Proteinoid-Poly(L-Lactic Acid) Copolymers and Nano/Micro-Hollow Particles for Biomedical Applications. J Nanomed Nanotechnol 5: 216. doi: 10.4172/21577439.1000216

Page 5 of 10

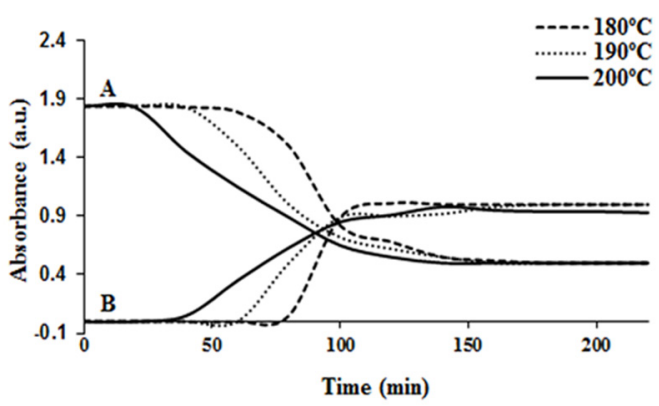

Figure 1: Thermal polycondensation kinetics of (L)glutamic acid and (L) phenylalanine to yield Prot3 at 180,190 and $200^{\circ} \mathrm{C}$ by two tests: ninhydrin test $(A)$ and Biuret test $(B)$.

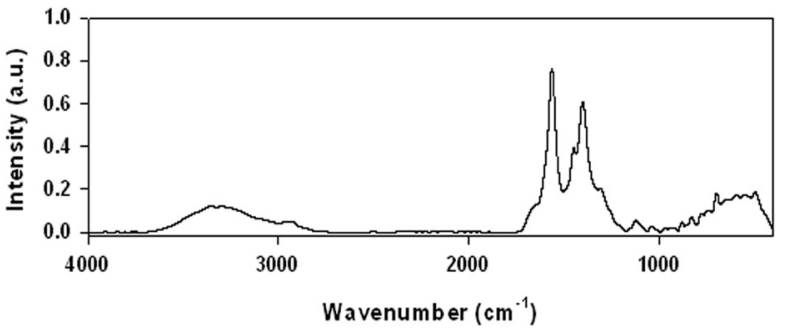

Figure 2: FTIR spectrum of Prot3. Characteristic peaks of $\mathrm{NH}$ stretching at 3360 and $2990 \mathrm{~cm}^{-1}$, amide $\mathrm{CO}$ stretching at $1565 \mathrm{~cm}^{-1}$, an amide $\mathrm{NH}$ bending band at $1450 \mathrm{~cm}^{-1}$ and $\mathrm{CO}$ bending at $500-700 \mathrm{~cm}^{-1}$ are shown.

\begin{tabular}{|c|c|}
\hline Polypeptide & [Carboxyl groups] (mmol/g) \\
\hline Albumin & 56 \\
\hline Prot1 & 150 \\
\hline Prot2 & 155 \\
\hline Prot3 & 90 \\
\hline Prot4 & 122 \\
\hline Prot5 & 88 \\
\hline Prot6 & 87 \\
\hline Prot7 & 80 \\
\hline Prot8 & 102 \\
\hline
\end{tabular}

Each experiment was performed 4 times, with an error of $0.5-2 \%$.

Table 3: Carboxyl group content in the proteinoids and albumin.

the polymerization procedure by thermal heating used here provides relatively long polymer chains. This fact can be an advantage for different uses later, since polymers with such high molecular weights are usually mechanically stronger and resemble natural proteins. Table 2 indicates that the lowest molecular weight was observed for the proteinoid composed of the single amino acid (L)glutamic acid (Prot1) and the highest one for the proteinoid composed of (L)glutamic acid, (L)aspartic acid and (L)lysine (Prot 5). Prot2, which was synthesized by microwave-assisted polymerization, reached an abundantly higher molecular weight. In this procedure, a $500 \mathrm{kDa}$ proteinoid chain was made, about twice the size of the thermal proteinoid. This kind of procedure gives us better yield over $60 \mathrm{~min}$, compared to the $3 \mathrm{~h}$ needed usually. It can be used further for higher molecular weights and more rigid proteinoids. However, unfortunately, this kind of proteinoid does not self-assemble into spherical-shaped particles.

All of the proteinoids exhibit optical activity, although the monomers are known to racemize during the thermal process [61].
This fact can become a benefit later in the design of a stereospecific drug carrier, for example.

The polymerization kinetics was examined over $220 \mathrm{~min}$ at three different temperatures $\left(180,190\right.$ and $\left.200^{\circ} \mathrm{C}\right)$ as illustrated in Figure 1. The results shown refer to the synthesis of Prot3, consisting of (L) glutamic acid and (L)phenylalanine. Similar results were observed for the other systems, Prot 1-8, as well. It can be seen that at all temperatures, the polymerization takes place mainly over the first $100 \mathrm{~min}$. After that, both ninhydrin (A) and Biuret (B) tests show no significant drop of the free amines (ninhydrin signal) or rise of the peptide bonds (Biuret signal). This figure also shows that as the temperature of the reaction was raised, the rate of the reaction increased. However, the preferred reaction temperature is $180^{\circ} \mathrm{C}$, as the yield of the reaction is higher since the amino acids decompose faster at the higher temperatures.

The proteinoids were also characterized by infrared spectroscopy. All proteinoids showed characteristic peaks of NH stretching at 3360 and $2990 \mathrm{~cm}^{-1}$, amide CO stretching at $1565 \mathrm{~cm}^{-1}$, an amide $\mathrm{NH}$ bending band at $1450 \mathrm{~cm}^{-1}$ and $\mathrm{CO}$ bending at $500-700 \mathrm{~cm}^{-1}$. A representative spectrum of Prot3 is showed in Figure 2.

\section{Carboxyl group analysis}

The presence of excess dicarboxylic amino acids in the synthesized proteinoids, aspartic acid and glutamic acid, provides acidic nature to the resulted polymers. This is also evident from carboxyl group content of the synthesized proteinoids where it shows higher values of 80-155 $\mathrm{mmol} / \mathrm{g}$ compared with albumin (Table 3). This is true also in Prot57 , where lysine is also a part of the polymer. Moreover, aspartic and glutamic acid moieties in the proteinoids, along with lysine, impart the hydrophilic nature of the whole proteinoid. The biodegradability rate of various amino acid polymers increases with their hydrophilicity [56]. Therefore, it is more appropriate to choose these proteinoids as ideal biomaterials for drug delivery applications.

\section{Thermal properties of the proteinoids}

The thermal properties of the proteinoids were investigated by DSC and TGA, as presented in Table 4 .

The melting temperatures of the different proteinoids range between $78-246^{\circ} \mathrm{C}$. The wide range of temperatures derives from the difference in the monomeric units used in each proteinoid. When using phenylalanine, as in Prot3, 4, 6 and 7, the resulted proteinoid gains significant rigidity in the overall structure, due to the aromatic rings which allow pi-stacking. Hence, these proteinoids melt at higher temperatures. When PLLA is incorporated into the proteinoid, as

\begin{tabular}{|c|c|c|c|c|}
\hline Proteinoid & $\operatorname{Tm}\left({ }^{\circ} \mathrm{C}\right)^{\mathrm{a}}$ & $\Delta \mathrm{Hm}(\mathrm{J} / \mathrm{g})^{\mathrm{a}}$ & $\operatorname{Tdec}\left({ }^{\circ} \mathrm{C}\right)^{b}$ & Weight loss (\%) \\
\hline Prot1 & 102 & -300.7 & 300 & 55 \\
\hline Prot2 & 89 & -428.7 & 297 & 57 \\
\hline Prot3 & 103 & -174.9 & 341 & 54 \\
\hline Prot4 & 217 & -183.4 & 330 & 25 \\
\hline Prot5 & 78 & -251.5 & 339 & 57 \\
\hline Prot6 & 241 & -90.1 & 373 & 47 \\
\hline Prot7 & 246 & -139.4 & 385 & 64 \\
\hline Prot8 & 117 & -420.5 & 268 & 47 \\
\hline PLLA $^{c}$ & 150 & -57.2 & 349 & 90 \\
\hline
\end{tabular}

aTm and $\Delta \mathrm{Hm}$ were measured by DSC; ${ }^{b} \mathrm{Tdec}$ (temperature of decomposition) was measured by TGA/DSC and refer to the exothermal peak in DSC; ${ }^{c} \mathrm{commercia}$ PLLA 2000 Da parameters were measured similar to the made proteinoids. Each experiment was performed 3 times, with an error of $1-1.5 \%$.

Table 4: Thermal properties of proteinoids produced by thermal polymerization. 
Citation: Kolitz-Domb M, Margel S (2014) Engineered Narrow Size Distribution High Molecular Weight Proteinoids, Proteinoid-Poly(L-Lactic Acid) Copolymers and Nano/Micro-Hollow Particles for Biomedical Applications. J Nanomed Nanotechnol 5: 216. doi: 10.4172/21577439.1000216

Page 6 of 10

\begin{tabular}{|c|c|c|}
\hline Solution & Particle size $(\mathbf{n m})^{\mathbf{c}}$ & Standard deviation (\%) \\
\hline Water & Over 3000 & 200 \\
\hline $\mathbf{N a C l ~} \mathbf{1 0}^{-5} \mathbf{N}$ & $196.2 \pm 23.9$ & 12.2 \\
\hline $\mathbf{N a C l ~} \mathbf{1 0}^{-3} \mathbf{N}$ & $486.2 \pm 54.3$ & 11.2 \\
\hline $\mathbf{N a C l} \mathbf{0 . 1 N}$ & $573.4 \pm 47.9$ & 17.5 \\
\hline $\mathbf{N a C l} \mathbf{1 N}$ & $1035.5 \pm 325.1$ & 31.4 \\
\hline PBS & $2151.0 \pm 204.3$ & 9.5 \\
\hline
\end{tabular}

${ }^{a}$ Particles were made of Prot $3 ;{ }^{b}$ particles made by heating to $80^{\circ} \mathrm{C}$ with mechanical stirring and then slow cooling to room temperature; "cthe particle size and size distribution were measured by DLS.

Table 5: Effect of self-assembly conditions on proteinoid particle size and size distribution. ${ }^{a, b}$

\begin{tabular}{|c|c|c|c|c|}
\hline $\begin{array}{c}\text { Heating time } \\
(\mathbf{m i n})\end{array}$ & Stirring $^{\mathbf{a}}$ & $\begin{array}{c}\text { Cooling } \\
\text { method }^{\boldsymbol{b}}\end{array}$ & Particle size (nm) $^{\mathbf{c}}$ & $\begin{array}{c}\text { Standard } \\
\text { deviation }^{(\%)}\end{array}$ \\
\hline 30 & - & slow & $722.5 \pm 84.8$ & 11.7 \\
\hline 60 & - & slow & $2293.7 \pm 277.8$ & 12.1 \\
\hline 30 & + & slow & $811.4 \pm 118.5$ & 14.6 \\
\hline 30 & - & fast & $1898.1 \pm 213.2$ & 11.2 \\
\hline
\end{tabular}

aStirring by a magnetic stirrer; ${ }^{b}$ slow cooling by removal of the heating and leaving the sample to cool to room temperature, fast cooling by refrigerating the sample; cthe particle size was measured by DLS.

Table 6: Effect of self-assembly reaction conditions on proteinoid particle size and size distribution
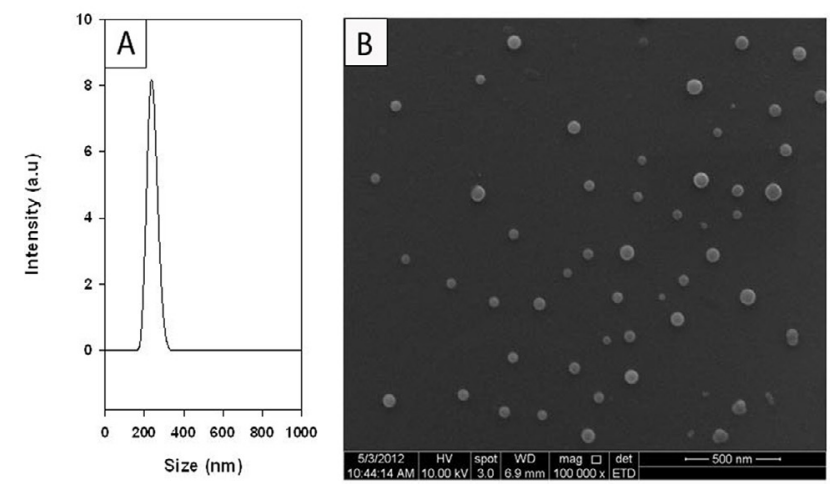

Figure 3: Hydrodynamic size histogram (A) and SEM image (B) of Prot8 particles.

in Prot8 compared to Prot 3 , the Tm rises mildly $\left(103\right.$ and $117^{\circ} \mathrm{C}$, respectively), due to the presence of 2000 Da rigid polymer chains in the overall proteinoid structure.

The TGA/DSC measurements of the proteinoids show decomposition temperatures of $268-385^{\circ} \mathrm{C}$. Most proteinoids lose at this temperature range around $50 \%$ of their weight. The decomposition measured at $400^{\circ} \mathrm{C}$ of most proteinoids is between $47-64 \%$, except Prot4 (25\%). Pure PLLA decomposes at $349^{\circ} \mathrm{C}$ almost completely (90\% weight loss). Prot8, composed of PLLA segments (10\%), has the lowest decomposition temperature of all proteinoids $\left(268^{\circ} \mathrm{C}\right)$. This can be explained by the non-uniformity of the structure of the whole proteinoid due to the inserted segments of $2000 \mathrm{Da}$ PLLA within the random segments of polymerized amino acids.

\section{Preparation and characterization of the proteinoid particles}

The crude proteinoids were self-assembled in a variety of environments, as mentioned before, in order to find the best conditions for forming the nano/micro particles. The desired particles, sphericallyshaped, have to be small and uniform in size through the whole sample.
Each self-assembly method gave particles of different properties, e.g., different size and size distribution. In order to compare between the different conditions, Prot 3 was examined. First, different salt solutions were investigated: double-distilled water, $10^{-5}-1 \mathrm{~N} \mathrm{NaCl}$ solutions and PBS at the same proteinoid concentration $(10 \mathrm{mg} / \mathrm{mL})$, heating for $30 \mathrm{~min}$ at $80^{\circ} \mathrm{C}$ and cooling slowly to room temperature, simply by removing the heat source and leaving the mixture to cool. As seen in Table 5, the smallest particle size was achieved using $10^{-5} \mathrm{~N} \mathrm{NaCl}$ solution, with a relatively good standard deviation of $12 \%$. In general, as the ionic strength of the salt solution decreases, the particle size and size distribution decreases [46]. When the self-assembly process takes place in water, in the absence of the salt, the particles formed are large, over $3 \mu \mathrm{m}$, and have a very wide size distribution. In PBS, the particles formed are around $2 \mu \mathrm{m}$ with a relatively narrow size distribution. This way, a large variety of proteinoid particles of different size and size distribution can be made, by changing their outside environment only.

In addition to the outside environment control, the effect of the reaction conditions on the size was checked by changing the heating, stirring and cooling parameters. Four proteinoid samples in water $(10$ $\mathrm{mg} / \mathrm{mL}$ ) were introduced to different conditions in terms of heating time after dissolving the proteinoid polymer, stirring and cooling method. The results are shown in Table 6. As seen, the smallest particles were produced by the first procedure: heating for $30 \mathrm{~min}$ and cooling slowly to room temperature. Overall, the different procedures gave particles of narrow size distributions.

Self-assembly of Prot8 was carried out in the best conditions found until now: $10^{-5} \mathrm{~N} \mathrm{NaCl}$ solution, heating at $80^{\circ} \mathrm{C}$ for $30 \mathrm{~min}$, followed by slow cooling to room temperature. The procedure produced spherical proteinoid particles of $103 \pm 11 \mathrm{~nm}$ hydrodynamic diameter and $70 \pm$ $15 \mathrm{~nm}$ dry diameter, as shown in Figure 3. The hydrodynamic diameter of these particles dispersed in water is illustrated by the typical light scattering measurement shown in Figure 3A. The dry diameter of the proteinoid particles is illustrated by the typical SEM photomicrograph shown in Figure 3B. The difference in the particle size between the SEM and the light scattering measurements is due to the fact that SEM measurements determine the dry diameter, whereas light scattering measurements takes into account the hydrated water layers adsorbed onto the particle's surface. As mentioned above, Prot 8 has small PLLA segments incorporated within the random polymerized amino acid segments. This fact grants the proteinoid a more hydrophobic backbone. These hydrophobic segments are packed better in the interior part of the spherical particles during the self-assembly precipitation process. The addition of the PLLA segments also leads to the formation of smaller size particles. For example, under similar preparation conditions Prot3, composed of (L)glutamic acid and (L)phenylalanine, provided particles of $196.2 \pm 23.9 \mathrm{~nm}$ while Prot8 composed of (L)glutamic acid, (L) phenylalanine and PLLA provided particles of $103 \pm 11 \mathrm{~nm}$ diameter.

It should also be noted that overall, the proteinoid particles maintain their size and size distribution upon change of the outside environment, given that the change is not by drastic $\mathrm{pH}$ values. This way, for instance, Prot8 particles preserve their size when transferred from water to PBS.

Density measurements indicated that all proteinoid particles possess a very low density, ranging from 0.001 to $0.014 \mathrm{~g} / \mathrm{mL}$ indicating that the particles formed are hollow, as already indicated for the proteinoids prepared by Fox et al. [17]. The hollow nature of the particles is significantly important for applications such as ultrasound imaging agents, drugs and dyes encapsulation, controlled released, etc.

As suggested in our and previous studies, the proteinoid forms 


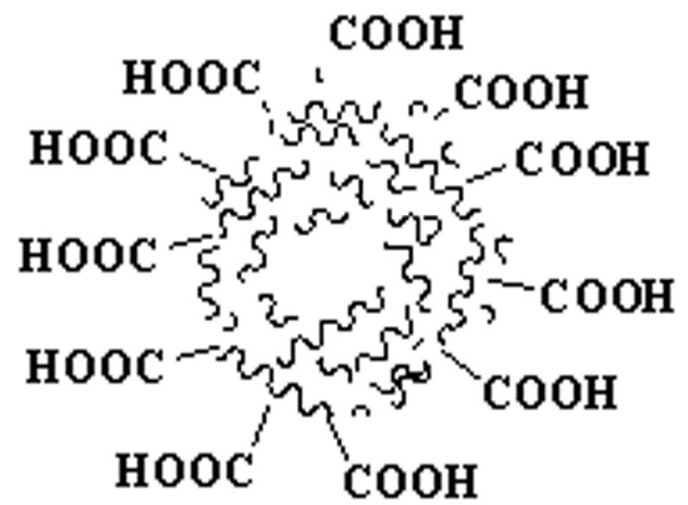

Figure 4: Schematic representation of the self-assembled proteinoid particles; hydrophobic moieties are represented by scribbled lines. When lysine is also a part of the proteinoid, as in Prot5-7, some carboxyl groups are exchanged with amine groups.

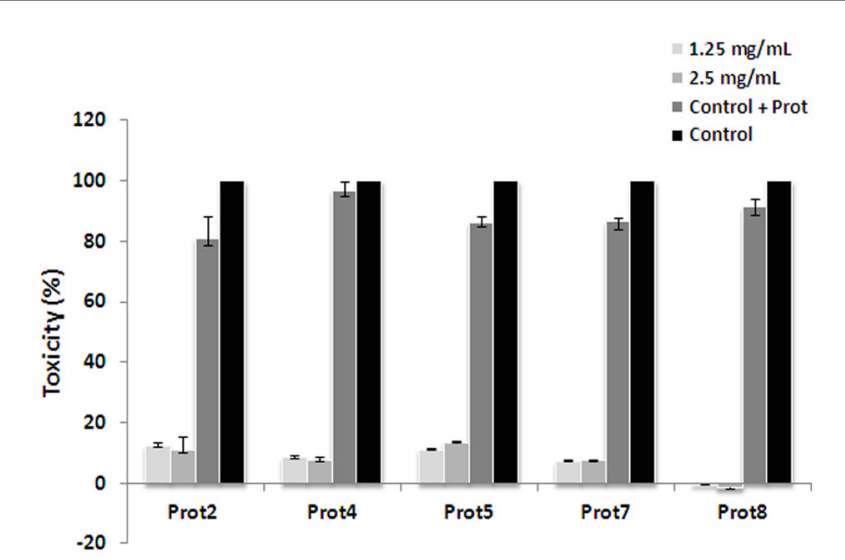

Figure 5: Cytotoxic effect of the proteinoid particles on colon adenocarcinoma LS174T cells measured by the LDH assay. Cells $(3 \times 105)$ were incubated with the proteinoid particles dispersed in PBS $(1.25 \mathrm{mg} / \mathrm{mL}$ and 2.5 $\mathrm{mg} / \mathrm{mL}$ ) according to the experimental section. Cells were incubated with Triton- $x-1001 \%$ as positive control (100\% toxicity). In addition, cells were incubated with Triton-x-100 $1 \%$ and each one of the proteinoids to revoke any interaction. Untreated cells (negative control) were similarly incubated. Each bar represents mean \pm standard deviations of 4 separate samples.

particles of different sizes according to the nature of its surrounding. The hydrophobic portions of the crude proteinoid are assembled within the particle matrix, while the polar hydrophilic groups (carboxylic acids and amines) are exposed to the aqueous environment, as illustrated in Figure 4 [56].

\section{Cellular cytotoxicity of the proteinoid particles by LDH assay}

In order to revoke cell toxicity of the new proteinoid particles, in vitro cytotoxicity of the particles was assessed by measuring the release of cytoplasmic lactate dehydrogenase (LDH) into the cell culture supernatants. $\mathrm{LDH}$ is an intracellular enzyme that catalyzes the reversible oxidation of lactate to pyruvate. Since $\mathrm{LDH}$ is mainly present in the cytosol, it is released into the supernatant only upon cell damage or lysis [60]. When tested by the LDH quantitative assay, Prot2, 4, 5, 7 and 8 particles dispersed in PBS at concentrations of 1.25 and $2.5 \mathrm{mg} / \mathrm{mL}$ had none, or minor cytotoxic effect on the human colon adenocarcinoma cell line LS174T (Figure 5). Treatment of the cells with Prot 2 and Prot 5 particles at both concentrations produced the highest
LDH levels (up to $13 \%$ toxicity), when compared to untreated (blank) cells, indicating minor toxicity of these proteinoids to this cell line. Prot8 had the lowest, or no cytotoxic effect on the cells treated with both concentrations. This proteinoid is therefore the most suitable for treating cells, considering its low toxicity.

\section{Particle stability}

The stability against agglomeration of the proteinoid particles dispersed in an aqueous phase $(1 \mathrm{mg} / \mathrm{mL})$ and kept in the refrigerator was examined at different time periods over 6 months as described in the experimental section. Overall, the proteinoid particles remain in the same size after 6 months in storage at $4^{\circ} \mathrm{C}$. Also, the degradation and /or dissolution of the proteinoid particles in the aqueous continuous phase was tested by the filtration centrifugation method and resulted in negative results in the filtrate, meaning no degradation or dissolution occurs at this temperature over 6 months. When lyophilized to dryness, the proteinoid particles can be redispersed in water completely while the particle size and size distribution remains the same. This means that the particles can be stored as a freeze-dried powder as well, and redispersed when needed, without the need to add cryoprotectants as mentioned in the literature [62].

\section{Encapsulation of different materials within the proteinoid particles}

Different materials were encapsulated within Prot8 according to the description in the experimental part. Fluorescein encapsulation was successful, as no fluorescein was detected in the aqueous filtrate. The fluorescein encapsulation process yields $425.2 \pm 21 \mathrm{~nm}$ particles, which were found stable for at least 6 months. Figure 6 exhibits the absorbance and emission spectra of free fluorescein compared to encapsulated fluorescein particles. A $14 \mathrm{~nm}$ red-shift of the absorbance spectrum of the fluorescent proteinoid particles, compared to free fluorescein in solution, was observed. This indicates that the physical binding to the proteinoid, which places the dye in a more hydrophobic environment, affects the dipole moment of the dye. The fluorescence and absorbance of the fluorescent proteinoid particles dispersed in PBS and stored at $4^{\circ} \mathrm{C}$ remain the same after 6 months.

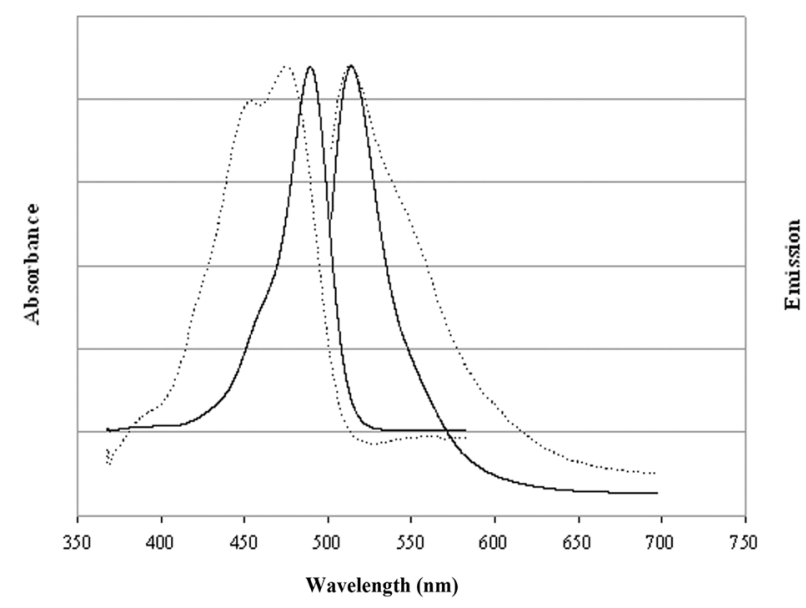

Figure 6: Absorbance and emission spectra of free fluorescein (dotted lines) and fluorescein proteinoid particles dispersed in water (solid lines). The maximum absorbance of free fluorescein and fluorescein encapsulated proteinoid particles occurs at approximately $475 \mathrm{~nm}$ and $489 \mathrm{~nm}$, respectively. The fluorescence emission maxima occur at approximately $513 \mathrm{~nm}$ and $514 \mathrm{~nm}$, respectively. 
Citation: Kolitz-Domb M, Margel S (2014) Engineered Narrow Size Distribution High Molecular Weight Proteinoids, Proteinoid-Poly(L-Lactic Acid) Copolymers and Nano/Micro-Hollow Particles for Biomedical Applications. J Nanomed Nanotechnol 5: 216. doi: 10.4172/21577439.1000216

Page 8 of 10
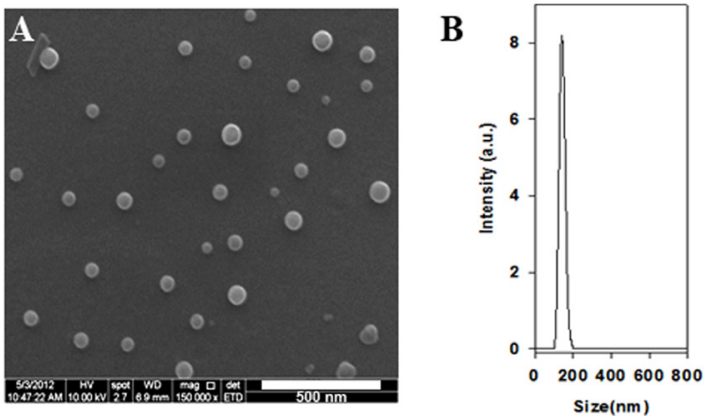

C

D
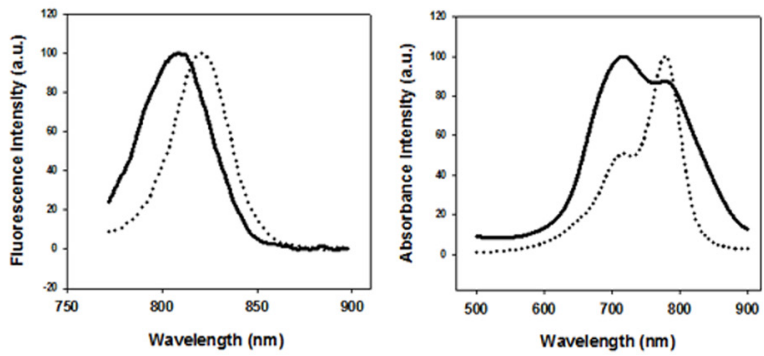

Figure 7: Characterization of the NIR fluorescent P(EF-PLLA) nanoparticles. A, B: SEM image and hydrodynamic size histogram of the NIR fluorescent $P(E F-P L L A)$ nanoparticles, respectively; C,D: emission and absorbance spectra of free ICG (dotted lines) and nanoparticles containing ICG (solid lines), respectively.

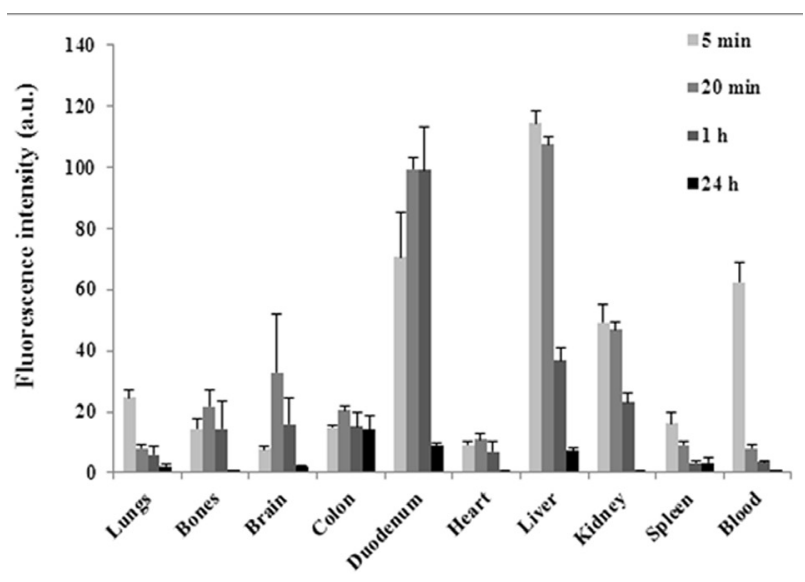

Figure 8: Fluorescence intensities of different organs taken at $5 \mathrm{~min}, 20$ min, $1 \mathrm{~h}$ and $24 \mathrm{~h}$ post i.v. injection into mice tail veins. 12 mice (each experiment group contained 3 mice) were anesthetized and treated with NIR fluorescent P(EF-PLLA) nanoparticles $(2 \mathrm{mg} / \mathrm{mL}, 0.01 \mathrm{mg} / \mathrm{kg}$ body weight per mouse). Blood was drawn and organs were harvested at each time point. 2 uninjected mice served as negative control. The experiment was repeated twice with similar results.

Similarly, the encapsulation of toluene was successful, as no organic separate phase was present at the end of the process. In this case, the proteinoid serves as a surfactant for dispersing the organic toluene droplets in water. No phase separation was observed within 6 months following the encapsulation. Particles containing toluene reached a size of $411.9 \pm 59.1 \mathrm{~nm}$. The encapsulation of solvent blue 59 dissolved in toluene resulted in slightly larger particles, $442.5 \pm 66.6 \mathrm{~nm}$. In this case, as in the encapsulation of toluene, no phase separation is observed over 6 months. When PFH is present during the particle formation, encapsulation yields $546.9 \pm 52.4 \mathrm{~nm}$ particles. Examination the $\mathrm{PFH}$ particles over $24 \mathrm{~h}$, shows a clear phase separation. Hence, the PFH particles can only serve immediate needs, such as ultrasound contrast agent [63].

Likewise, the NIR FDA-approved ICG was encapsulated successfully in the Prot8 nanoparticles. Figures 7A and 7B show that the dry (A) and hydrodynamic (B) diameters of the NIR fluorescent Prot8 nanoparticles are $70 \pm 15 \mathrm{~nm}$ and $145 \pm 20 \mathrm{~nm}$, respectively. Figure 7C and 7D exhibit the fluorescence and absorbance spectra of the NIR fluorescent Prot8 nanoparticles compared to those of the free dye in solution. The absorbance spectra show no shift in the absorbance. However, due to the dye encapsulation process the maximal absorbance peak of the free ICG became minimal and the minimal peak of the free dye became maximal after encapsulation, since the ICG molecules get close to each other inside the nanoparticle interior and aggregation may occur and cause this change in absorbance [64,65]. Moreover, a blue-shift of $12 \mathrm{~nm}$ in the emission spectrum of the NIR fluorescent nanoparticles compared to the free ICG in solution was also observed, due to the dye molecule aggregation inside the particle.

\section{Biodistribution in a mouse model}

NIR fluorescent Prot8 nanoparticles $(2 \mathrm{mg} / \mathrm{mL}, 0.01 \mathrm{mg} / \mathrm{kg}$ body weight per mouse) were injected into mice through the tail vein. Organs from mice were harvested and blood was drawn $5 \mathrm{~min}, 20 \mathrm{~min}, 1 \mathrm{~h}$ and $24 \mathrm{~h}$ post injection of the nanoparticles into the tail vein. The calculated fluorescence intensities of the lungs, bones, brain, colon, duodenum, heart, liver, kidney, spleen and blood screening are shown in Figure 8. Evidently, the results show that the nanoparticles penetrated and were found in all organs. It is shown clearly that by $20 \mathrm{~min}$ the majority of the inserted quantity of the fluorescent nanoparticles is cleared from the blood. The nanoparticles concentrate mostly at the liver and are possibly evacuated from the body. It is also apparent that the nanoparticles pass the blood-brain barrier (BBB), since they are found in the brain at 20 min post injection. This may open up a scope of drug targeting to the brain for drug molecules which are usually blocked. Overall, it was demonstrated that following a single i.v. injection of the nanoparticles, fluorescence intensity at all organs decreased over time, and only traces of fluorescence could be seen after $24 \mathrm{~h}$.

\section{Conclusions}

In the present study, 9 new proteinoids were prepared using (L) glutamic acid, (L)aspartic acid, (L)phenylalanine, (L)lysine and PLLA. The polymerization was carried out by a simple straight-forward condensation polymerization in heat. The optimal conditions for polymerization were tested, including changing the temperature and using microwave radiation. The proteinoids made are of high molecular weights and possess optical activity, which can be later used in specific drug delivery using chirality. The proteinoids are thermally stable and each proteinoid has enough carboxylic acid and/or amine functional groups, which can be later used to bind desired molecules, such as drugs and dyes. The incorporation of 2000 Da PLLA into the proteinoid backbone presented a stable proteinoid as well. Proteinoids were manipulated in several ways to give proteinoid sphere-shaped nano/micro-particles, and to optimize this process. Specific conditions were found for the production nano hollow particles of narrow size distribution. The incorporation of PLLA segments into the proteinoids increased the hydrophobic interior part and resulted in smaller size hollow particles. The particles were found to be non-toxic and stable over time. Also, encapsulation of different materials was carried 
Citation: Kolitz-Domb M, Margel S (2014) Engineered Narrow Size Distribution High Molecular Weight Proteinoids, Proteinoid-Poly(L-Lactic Acid) Copolymers and Nano/Micro-Hollow Particles for Biomedical Applications. J Nanomed Nanotechnol 5: 216. doi: 10.4172/21577439.1000216

out, giving organic-filled particles and fluorescent particles. Most importantly, ICG, a NIR fluorescent FDA-approved dye for imaging, was successfully encapsulated and the particles were found in many organs after injection to mice.

In summary, proteinoid formation and cytotoxicity tests indicate that these particles are suitable for further in vivo testing. Our future plans include further optimization of the particles and in vivo imaging in various animal models, to test the extent of targeting. We also plan to encapsulate within the optimal proteinoid particles other fluorescent dyes and anticancer drugs such as paclitaxel and/or doxorubicin, so that the particles may be used for combined imaging and therapy applications.

\section{Acknowledgement}

The authors would like to thank Dr. Igor Grinberg for preforming the LDH tests and the biodistribution tests, Dr. Enav Corem for the help in the fluorescein encapsulation and Dr. Ronen Yehuda for performing the Maestro imaging.

\section{References}

1. Asmus LR, Gurny R, Möller M (2011) Solutions for lipophilic drugs: a biodegradable polymer acting as solvent, matrix, and carrier to solve drug delivery issues. Int J Artif Organs 34: 238-242.

2. Bernards DA, Desai TA (2010) Nanotemplating of biodegradable polymer membranes for constant-rate drug delivery. Adv Mater 22: 2358-2362.

3. Leone-Bay A, Ho KK, Agarwal R, Baughman RA, Chaudhary K, et al. (1996) 4-[4-[(2-Hydroxybenzoyl)amino]phenyl]butyric acid as a novel oral delivery agent for recombinant human growth hormone. J Med Chem 39: 2571-2578.

4. Leone-Bay A, Mclnnes C, Wang N, DeMorin F, Achan D, et al. (1995) Microsphere formation in a series of derivatized alpha-amino acids: properties, molecular modeling, and oral delivery of salmon calcitonin. J Med Chem 38: 4257-4262.

5. Leone-Bay A, Santiago N, Achan D, Chaudhary K, DeMorin F, et al. (1995) $\mathrm{N}$-acylated alpha-amino acids as novel oral delivery agents for proteins. J Med Chem 38: 4263-4269.

6. Lu Y, Chen SC (2004) Micro and nano-fabrication of biodegradable polymers for drug delivery. Adv Drug Deliv Rev 56: 1621-1633.

7. Shikanov A, Kumar N, Domb AJ (2005) Biodegradable polymers: An update. Isr J Chem 45: 393-399.

8. Kumar D (2002) Biodegradable Polymers. In: Encyclopedia of Polymer Science and Technology. Hoboken, NJ, Wiley Interscience.

9. Cohen-Arazi N, Hagag I, Kolitz M, Domb AJ, Katzhendler J (2011) Biodegradable Polymers Derived from Amino Acids for Biological Applications. Adv Sci Techno 76: $30-35$

10. Cohen-Arazi N, Katzhendler J, Kolitz M, Domb Al (2008) Preparation of New alpha-Hydroxy Acids Derived from Amino Acids and Their Corresponding Polyesters. Macromolecules 41: 7259-7263.

11. Kolitz M, Cohen-Arazi N, Hagag I, Katzhendler J, Domb AJ (2009) Biodegradable Polyesters Derived from Amino Acids. Macromolecules 42: 4520-4530.

12. Fox SW (1960) How Did Life Begin? Science 132: 200-208.

13. Fox SW (1974) Proteinoid Theory of Origin of Life and Competing Ideas. Am. Biol. Teach. 36: 161-172.

14. Fox SW (1995) Thermal synthesis of amino acids and the origin of life. Geochim Cosmochim Acta 59: 1213-1214.

15. Fox SW, Jungck JR, Nakashima T (1974) From proteinoid microsphere to contemporary cell: formation of internucleotide and peptide bonds by proteinoid particles. Orig Life 5: 227-237.

16. Fox SW, Mccauley RJ, Fukushim.T, Windsor CR, Montgome Po (1967) Selective Action in Boundaries of Particles of Thermal Proteinoid. Fed Proc 26: 749

17. Fox SW, Nakashima T, Przybylski A Syren RM (1982) The Updated Experimental Proteinoid Model. Int J Quantum Chem 22: 195-204.

18. Fox SW, Waehneldt TV (1968) The thermal synthesis of neutral and basic proteinoids. Biochim Biophys Acta 160: 246-249.
19. FOX SW, Harada K (1958) Thermal copolymerization of amino acids to product resembling protein. Science 128: 1214.

20. Fox SW, Harada K (1959) The Thermal Copolymerization of Amino Acids Common to Protein. J Am Chem Soc 82: 3745-3751.

21. Fox SW, Harada K (1960) Thermal copolymerization of amino acids in the presence of phosphoric acid. Arch Biochem Biophys 86: 281-285.

22. Fox SW, Harada K (1962) Thermal Polymerization of Amino Acid Mixtures Containing Aspartic Acid or a Thermal Precursor of Aspartic Acid. US Patent $3,052,655$

23. Fox SW, Harada K (1963) Method of Making Copolymers of Amino Acids Containing Glutamic Acid. US Patent 3,076,790.

24. Harada K, Fox SW (1958) The Thermal Condensation of Glutamic Acid and Glycine to Linear Peptides. J Am Chem Soc 80: 2694-2697.

25. Harada K, Matsuyama M (1979) Polycondensation of thermal precursors of amino acids and characterization of constituent amino acids. Biosystems 11 : 47-53.

26. Slager J, Domb AJ (2003) Biopolymer stereocomplexes. Adv Drug Deliv Rev 55: $549-583$

27. Kohn J, Langer R (1987) Polymerization Reactions Involving the Side-Chains of Alpha-L-Amino Acids. J Am Chem Soc 109: 817-820.

28. Matsuno K (1984) Electrical excitability of proteinoid microspheres composed of basic and acidic proteinoids. Biosystems 17: 11-14.

29. Przybylski AT (1985) Excitable cell made of thermal proteinoids. Biosystems 17: 281-288.

30. Przybylski AT, Fox SW (1984) Excitable artificial cells of proteinoid. App Biochem Biotechnol 10: 301-307.

31. Quirk S (2013) Enhanced catalytic activity from proteinoid microspheres. J Biomed Mater Res A 101: 1133-1143.

32. Blackwell HE (2003) Out of the oil bath and into the oven--microwave-assisted combinatorial chemistry heats up. Org Biomol Chem 1: 1251-1255.

33. Kempe K, Becer CR, Schubert US (2011) Microwave-assisted polymerizations: recent status and future perspectives. Macromolecules 44: 5825-5842.

34. Fang XM, Simone CD, Vaccaro E, Huang SJ, Scola DA (2002) Ring-opening polymerization of epsilon-caprolactam and epsilon-caprolactone via microwave irradiation. J Polym Sci Part A: Polym Chem 40: 2264-2275.

35. Liao LQ, Liu LJ, Zhang C, He F, Zhuo RX, et al. (2002) Microwave-assisted ring-opening polymerization of epsilon-caprolactone. J Polym Sci Part A: Polym Chem 40: 1749-1755.

36. Yu ZJ, Liu LJ, Zhuo RX (2003) Microwave-improved polymerization of epsiloncaprolactone initiated by carboxylic acids. J Polym Sci Part A: Polym Chem 41: 13-21.

37. Mallakpour S, Habibi S (2003) Microwave-promoted synthesis of new optically active poly(ester-imide)s derived from N,N '-(pyromellitoyl)-bis-L-leucine diacid chloride and aromatic diols. Eur Polym J 39: 1823-1829.

38. Zhang C, Liao LQ, Liu LJ (2004) Rapid ring-opening polymerization of D, Llactide by microwaves. Macromol. Rapid Commun 25: 1402-1405.

39. Vogel BM, Mallapragada SK, Narasimhan B (2004) Rapid synthesis of polyanhydrides by microwave polymerization. Macromol. Rapid Commun 25 330-333.

40. Wiesbrock F, Hoogenboom R, Schubert US (2004) Microwave-assisted polymer synthesis: State-of-the-art and future perspectives. Macromol. Rapid Commun 25: 1739-1764

41. Bahn PR, Pappelis A, Bozzola J (2006) Protocell-like microspheres from thermal polyaspartic acid. Orig Life Evol Biosph 36: 617-619.

42. Milstein SJ, Kantor ML (1997). Proteinoid Microspheres and Methods for Preparation and Use Thereof. US Patent 5,601,846.

43. Bamnolker H, Nitzan B, Gura S, Margel S (1997) New solid and hollow, magnetic and non-magnetic, organic-inorganic monodispersed hybrid microspheres: synthesis and characterization. J Mater Sci Lett 16: 1412-1415.

44. Syren RM, Sanjur A, Fox SW (1985) Proteinoid microspheres more stable in hot than in cold water. Biosystems 17: 275-280. 
Citation: Kolitz-Domb M, Margel S (2014) Engineered Narrow Size Distribution High Molecular Weight Proteinoids, Proteinoid-Poly(L-Lactic Acid) Copolymers and Nano/Micro-Hollow Particles for Biomedical Applications. J Nanomed Nanotechnol 5: 216. doi: 10.4172/21577439.1000216

45. Bae SK, Kim JD (2003) Aggregation behaviors and their $\mathrm{pH}$ sensitivity of cholesterol-conjugated proteinoids composed of glutamic acid and aspartic acid matrix. J Biomed Mater Res A 64: 282-290.

46. Kokufuta E, Sakai H, Harada K (1983) Factors controlling the size of proteinoid microspheres. Biosystems 16: 175-181.

47. Steiner S, Rosen R (1990) Delivery Systems for Pharmacological Agents Encapsulated with Proteinods. US Patent 4,925,673.

48. Müller-Herold U, Nickel G (1994) The stability of proteinoid microspheres. Biosystems 33: 215-220.

49. Nakashima T (1987) Metabolism of proteinoid microspheres. Top Curr Chem 139: 57-81.

50. Quirk S (2007) Triggered Release from Proteinoid Microspheres. US Patent $02314400 \mathrm{~A} 1$.

51. Quirk S (2009) Triggered release of small molecules from proteinoid microspheres. J Biomed Mater Res A 91: 391-399.

52. Quirk S (2010) Triggered release from peptide-proteinoid microspheres. J Biomed Mater Res A 92: 877-886.

53. Toublan FJJ, Dibbern E, Argadine HM, Greenleaf JF, Simari RD, et al. (2004) Electrostatic adhesion of polyelectrolytes and colloids on protein microspheres. Abstr Pap Am Chem S 228: U350-U350.

54. Janairo G, Sy ML, Yap L, Llanos-Lazaro N, Robles J (2011) Determination of the Sensitivity Range of Biuret Test for Undergraduate Biochemistry Experiments. e-JST 5: 77-83.

55. Diaz J, Lliberia JL, Comellas L, Broto-Puig F (1996) Amino acid and amino sugar determination by derivatization with 6 -aminoquinolyl-N-hydroxysuccinimidyl carbamate followed by high-performance liquid chromatography and fluorescence detection. J Chromatogr A 719: 171-179.
56. Madhan Kumar AB1, Panduranga Rao K (1998) Preparation and characterization of $\mathrm{pH}$-sensitive proteinoid microspheres for the oral delivery of methotrexate. Biomaterials 19: 725-732.

57. Keki S, Bodnar I, Borda J, Deák G, Zsuga M (2001) Fast Microwave-Mediated Bulk Polycondensation of d, I-Lactic Acid. Macromol Rapid Commun 22: 10631065.

58. Heiskanen $\mathrm{J}$ (1992) Comparison of three methods for determining the particle density of soil with liquid pycnometers. Commun. Soil Sci Plant Anal 23: 841 846.

59. Epsztejn S, Glickstein H, Picard V, Slotki IN, Breuer W, et al. (1999) H-ferritin subunit overexpression in erythroid cells reduces the oxidative stress response and induces multidrug resistance properties. Blood 94: 3593-3603.

60. Decker T, Lohmann-Matthes ML (1988) A quick and simple method for the quantitation of lactate dehydrogenase release in measurements of cellular cytotoxicity and tumor necrosis factor (TNF) activity. J Immunol Methods 115 $61-69$

61. Dose K (1974) Chemical and catalytical properties of thermal polymers of amino acids (proteinoids). Orig Life 5: 239-252.

62. Ma X, Santiago N, Chen YS, Chaudhary K, Milstein SJ, et al. (1994) Stability study of drug-loaded proteinoid microsphere formulations during freeze-drying. J Drug Target 2: 9-21.

63. Quay SC (2004) Ultrasound contrast agents including protein stabilized microspheres of perfluoropropane, perfluorobutane or perfluoropentane. J Acoust Soc Am 116: 1335-1336.

64. Haritoglou C, Freyer W, Priglinger SG, Kampik A (2006) Light absorbing properties of indocyanine green (ICG) in solution and after adsorption to the retinal surface: an ex-vivo approach. Graefes Arch Clin Exp Ophthalmol 244: 1196-1202.

65. Zweck J, Penzkofer A (2001) Microstructure of indocyanine green J-aggregates in aqueous solution. Chem Phys 269: 399-409. 